\title{
Antibiotic Resistance in Shiga Toxigenic Escherichia coli Isolates from Surface Waters and Sediments in a Mixed Use Urban Agricultural Landscape
}

\author{
Yvonne Ma ${ }^{1,+}{ }^{+}$, Jessica Chen ${ }^{1,+}$, Karen Fong ${ }^{1}$, Stephanie Nadya ${ }^{1}$, Kevin Allen ${ }^{1}$, Chad Laing ${ }^{2}$, Kim Ziebell ${ }^{3}$, \\ Ed Topp ${ }^{4}$, Laura M. Carroll ${ }^{5}$, Martin Wiedmann ${ }^{5}$, Pascal Delaquis ${ }^{6}$ and Siyun Wang ${ }^{1, *(\mathbb{D})}$ \\ 1 Faculty of Land and Food Systems, University of British Columbia, Vancouver, BC V6T 1Z4, Canada; \\ yvonne.ma@ubc.ca (Y.M.); jlc232@gmail.com (J.C.); karen.fong@ubc.ca (K.F.); \\ stephanienadya@gmail.com (S.N.); kevin.allen@ubc.ca (K.A.) \\ 2 National Centre for Animal Diseases, Canadian Food Inspection Agency, Lethbridge, AB T1J 3Z4, Canada; \\ chad.laing@canada.ca \\ 3 Laboratory for Foodborne Zoonoses, Public Health Agency of Canada, Guelph, ON N1G 3W4, Canada; \\ kim.ziebell@canada.ca \\ 4 London Research and Development Centre, Agriculture and Agri-Food Canada, \\ London, ON N5V 4T3, Canada; ed.topp@canada.ca \\ 5 Department of Food Science, Cornell University, Ithaca, NY 14853, USA; laura.carroll@embl.de (L.M.C.); \\ martin.wiedmann@cornell.edu (M.W.) \\ 6 Summerland Research and Development Centre, Agriculture and Agri-Food Canada, \\ Summerland, BC V0H 1Z0, Canada; pascal.delaquis@canada.ca \\ check for \\ updates \\ * Correspondence: siyun.wang@ubc.ca \\ + Authors contributed equally to the work.
}

Citation: Ma, Y.; Chen, J.; Fong, K.; Nadya, S.; Allen, K.; Laing, C.; Ziebell, K.; Topp, E.; Carroll, L.M.; Wiedmann, M.; et al. Antibiotic Resistance in Shiga Toxigenic Escherichia coli Isolates from Surface Waters and Sediments in a Mixed Use Urban Agricultural Landscape. Antibiotics 2021, 10, 237. https://doi.org/ 10.3390/antibiotics10030237

Academic Editor: Birgit Pruess

Received: 21 January 2021

Accepted: 19 February 2021

Published: 26 February 2021

Publisher's Note: MDPI stays neutral with regard to jurisdictional claims in published maps and institutional affiliations.

Copyright: $\odot 2021$ by the authors. Licensee MDPI, Basel, Switzerland. This article is an open access article distributed under the terms and conditions of the Creative Commons Attribution (CC BY) license (https:// creativecommons.org/licenses/by/ $4.0 /)$.

\begin{abstract}
Antibiotic resistance (AR) phenotypes and acquired resistance determinants (ARDs) detected by in silico analysis of genome sequences were examined in 55 Shiga toxin-producing Escherichia coli (STEC) isolates representing diverse serotypes recovered from surfaces waters and sediments in a mixed use urban/agricultural landscape in British Columbia, Canada. The isolates displayed decreased susceptibility to florfenicol (65.5\%), chloramphenicol (7.3\%), tetracycline $(52.7 \%)$, ampicillin $(49.1 \%)$, streptomycin $(34.5 \%)$, kanamycin $(20.0 \%)$, gentamycin $(10.9 \%)$, amikacin $(1.8 \%)$, amoxicillin/clavulanic acid $(21.8 \%)$, ceftiofur $(18.2 \%)$, ceftriaxone $(3.6 \%)$, trimethoprimsulfamethoxazole $(12.7 \%)$, and cefoxitin $(3.6 \%)$. All surface water and sediment isolates were susceptible to ciprofloxacin, nalidixic acid, ertapenem, imipenem and meropenem. Eight isolates $(14.6 \%)$ were multidrug resistant. ARDs conferring resistance to phenicols $(f l o R)$, trimethoprim $(d f r A)$, sulfonamides (sul1/2), tetracyclines $($ tet $A / B)$, and aminoglycosides (aad $A$ and $a p h$ ) were detected. Additionally, narrow-spectrum $\beta$-lactamase blaTEM-1b and extended-spectrum AmpC $\beta$-lactamase (cephalosporinase) blaCMY-2 were detected in the genomes, as were replicons from plasmid incompatibility groups IncFII, IncB/O/K/Z, IncQ1, IncX1, IncY and Col156. A comparison with surveillance data revealed that AR phenotypes and ARDs were comparable to those reported in generic E. coli from food animals. Aquatic environments in the region are potential reservoirs for the maintenance and transmission of antibiotic resistant STEC, associated ARDs and their plasmids.
\end{abstract}

Keywords: Shiga toxin-producing E. coli; antimicrobial resistance; whole-genome sequencing; bacteriophages

\section{Introduction}

The Shiga toxigenic Escherichia coli (STEC) pathotype is characterized by the production of one or more cytotoxic Shiga-like toxins, small proteins encoded by a temperate lambdoid phage on the main chromosome. Infection with STEC causes diseases of variable severity, ranging from comparatively mild to acute hemorrhagic diarrhea, and potentially 
fatal thrombotic thrombocytopenic purpura or hemolytic uremic syndrome (HUS). Foodborne outbreaks have been reported with increasing frequency since two epidemiologically significant disease clusters were definitively associated with the consumption of red meat in the US in 1983 [1], and STEC are now recognized as significant water and foodborne threats to global public health [2-4]. A recent food-borne source attribution analysis performed using disease and surveillance data from several countries showed that foods from a broad range of categories are implicated in outbreaks [5]. Moreover, the analysis confirmed that plant-based foods, primarily fresh fruits and vegetables, are now significant vehicles for the foodborne transmission of STEC, notably in the Americas.

The advisability of antibiotic therapies for the management of STEC infections is the subject of enduring debate due to reports of antibiotic-induced toxin release from dead cells or by the induction of Shiga toxin-converting prophage [6]. For example, the fluoroquinolone antibiotic ciprofloxacin was shown to cause the induction of bacteriophage and Shiga toxin production in both in vivo and in vitro studies in a mouse model [7]. However, definitive evidence of causative association with clinical symptoms of human STEC disease remains elusive. A review of available data from clinical studies led Agger et al. [8] to conclude that it remains unclear whether the administration of protein and cell wall synthesis inhibitors influences the duration of diarrhea or the development of HUS. Moreover, a mixture of ciprofloxacin and the carbapenem meropenem was successfully used to alleviate the symptoms of HUS in patients infected with E. coli serotype O104:H4 during a major foodborne outbreak in Germany [9]. Nevertheless, antibiotic therapies are presently contraindicated by clinicians and public health authorities in some jurisdictions, primarily in the developed world. There is little doubt, however, that antibiotics are often administered to patients infected with STEC where diagnosis is delayed or masked by infections caused by other agents of gastrointestinal disease. Moreover, their use persists in many countries, including Canada, for the control and treatment of livestock diseases caused by STEC, notably edema disease in weaned piglets and watery diarrhea in calves [10].

The persistent therapeutic use of antibiotics in human and veterinary medicine or for growth promotion in animal production has contributed to the emergence and proliferation of antibiotic resistant bacteria (ARB), including zoonotic pathogenic species [11]. The global emergence of acquired resistance and concomitant decline in efficacy are anticipated to lessen the therapeutic value of present-day antibiotics used in human and veterinary medicine, with potentially dire social and economic consequences [12]. A report by the World Health Organization highlights the importance of resistance in E. coli due to the prevalence and wide spectrum of infections caused by variable pathotypes of the species [13]. Early clinical human STEC stains (primarily of serotype O157:H7) were generally susceptible to antibiotics, but there is evidence that antibiotic resistance (AR) is increasingly common in the pathotype [14-19]. Some isolates are reported to be multidrug resistant (MDR) according to the proposed standardized terminology for acquired resistance in Magiorakos et al. [20], whereby so-designated bacteria are not susceptible to more than one agent in more than three antimicrobial classes specified for the family Enterobacteriaceae. E. coli share many enzymatic and non-enzymatic resistance mechanisms with other species of Gram-negative bacteria, including intrinsic mechanisms involving inactivating enzymes or efflux pumps or mechanisms acquired by the horizontal transfer of antibiotic resistance determinants (ARDs) on mobile genetic elements leading, to the impaired absorption, modification of the antibiotic target by mutation or post-translational modification, or inactivation by hydrolysis or other chemical means [21]. Horizontal transfer is favoured by integrons, site-specific recombination systems consisting of two conserved segments flanking a central region containing "cassettes" of functional genes [22]. Integrons of relevance in the development of antibiotic resistance in enteric bacterial pathogens are primarily borne on self-replicating plasmids [23]. Most of the 27 recognized main incompatibility (Inc) groups of plasmids in Enterobacteriaceae have been associated with resistance to antibiotics in E. coli, including STEC [24-26]. 
Nucleic acid sequencing and in silico analysis are widely used to characterize ARB and associated ARDs in species recovered from disparate environments $[27,28]$. The current knowledge about AR and ARDs in STEC is largely based on the analysis of human clinical specimens or isolates obtained through surveillance systems that primarily target livestock species and meat products. In contrast, little is known about resident or transient STEC populations in natural or anthropogenically impacted terrestrial and aquatic ecosystems. The latter can serve as secondary reservoirs for transmission to humans by indirect routes, notably the consumption of food crops grown in environments susceptible to pollution from urban or agricultural sources [29]. The assessment of potential exposure risks and the development of mitigation measures require knowledge about the abundance and distribution of ARB and ARDs in such environments. In the present work, we report on $A R$ phenotypes and associated ARDs in STEC recovered from surface waters in the Fraser Valley of British Columbia, Canada, an urban-agricultural region that supports intensive livestock farming and food crop production under irrigation.

\section{Results}

\subsection{Antibiotic Resistance Phenotypes of STEC Isolates Recovered from Surface Water} and Sediments

The proportion of 55 STEC isolates resistant, of intermediate resistance or susceptible to eighteen antibiotics is shown in Figure 1 and individual resistance phenotypes are provided in Table 1. All isolates were susceptible to the quinolone nalidixic acid (NAL), the fluoroquinolone ciprofloxacin (CIP) and carbapenems imipenem (IPM), ertapenem (ETP) and meropenem (MEM). The percentage of isolates resistant or of intermediate resistance to the other classes/groups of antibiotics examined were (in decreasing order of abundance): phenicols florfenicol (FFC), $65.5 \%$ and chloramphenicol (CHL), $7.3 \%$; tetracycline (TET), 52.7\%; penicillin ampicillin (AMP), 49.1\%; aminoglycosides streptomycin (STR) $34.5 \%$, kanamycin (BCN) 20.0\%, gentamicin (GEN) 10.9\%, and amikacin (AMK) 1.8\%; penicillin + $\beta$-lactam inhibitor amoxicillin/clavulanic acid (AMC), 21.8\%; third generation cephalosporins ceftiofur (TIO), $18.2 \%$ and ceftriaxone (CRO), 3.6\%; folate pathway inhibitor trimethoprim-sulfamethoxazole (SXT), 12.7\%; and the cephamycin cefoxitin (FOX), 3.6\%. Resistance at concentrations examined in this work was limited to 10 of the antibiotics including FFC (16.4\% of isolates), STR (23.6\%), TET (18.2\%), AMP $(20.0 \%)$, SXT (12.7\%), BCN $(7.3 \%)$, AMC (7.3\%), CHL (3.6\%), TIO (3.6\%) and FOX (1.8\%). According to the proposed standardized terminology for acquired resistance profiles specified for the family Enterobacteriaceae in Magiorakos et al. [20], 10 isolates (18.2\%) were pansusceptible, 37 (67.2\%) were of intermediate resistance and eight (14.6\%) were MDR. Four of the MDR isolates were from serogroup O111 and the most complex phenotype was found in isolate 385-O111:NM, which was resistant to nine antibiotics $\left(\mathrm{AMP}^{\mathrm{R}} \mathrm{AMC}^{\mathrm{R}} \mathrm{CHL}^{\mathrm{R}} \mathrm{FFC}^{\mathrm{R}} \mathrm{FOX}^{\mathrm{R}} \mathrm{STR}^{\mathrm{R}} \mathrm{SXT}^{\mathrm{R}} \mathrm{TET}^{\mathrm{R}}\right.$ $\mathrm{TIO}^{\mathrm{R}}$ ) and showed intermediate resistance to two additional aminoglycosides $\left(\mathrm{CRO}^{\mathrm{I}} \mathrm{GEN}^{\mathrm{I}}\right)$ and one third generation cephalosporin $\left(\mathrm{BCN}^{\mathrm{I}}\right)$. 


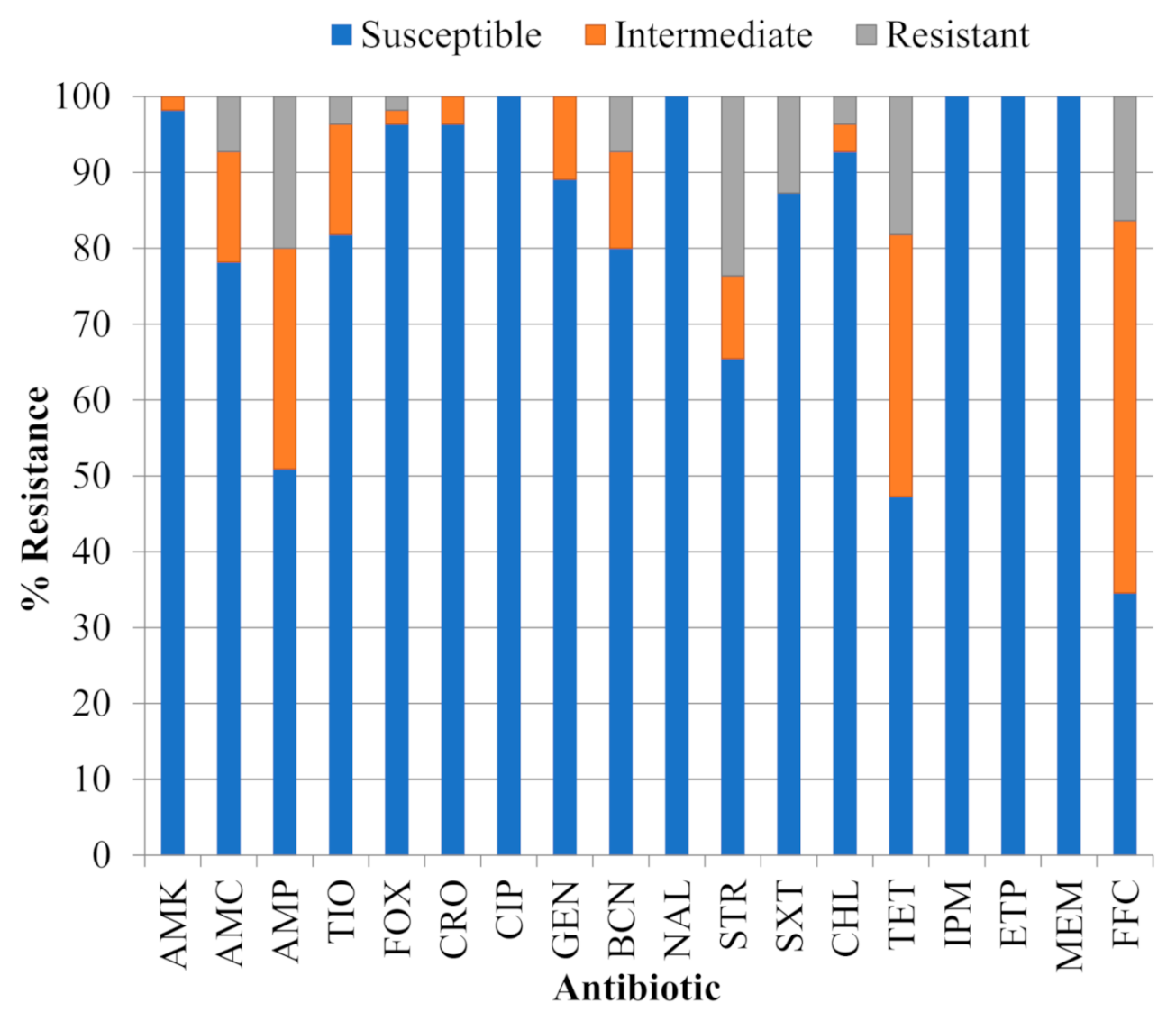

Figure 1. Proportion of 55 Shiga toxigenic Escherichia coli (STEC) isolates that were susceptible, of intermediate resistance or resistant to eighteen antibiotics: amikacin (AMK), amoxicillin/clavulanic acid (AMC), ampicillin (AMP), ceftiofur (TIO), cefoxitin (FOX), ceftriaxone (CRO), ciprofloxacin $(\mathrm{CIP})$, gentamicin (GEN), kanamycin (BCN), nalidixic acid (NAL), streptomycin (STR), trimethoprimsulfamethoxazole (SXT), chloramphenicol (CHL), tetracycline (TET), imipenem (IPM), ertapenem (ETP), meropenem (MEM) and florfenicol (FFC).

Table 1. Antibiotic resistance phenotypes of 55 STEC isolates from surface water and sediments in the Lower Mainland of British Columbia, Canada.

\begin{tabular}{|c|c|c|}
\hline $\begin{array}{l}\text { Isolate Number } \\
\text { and Serotype }\end{array}$ & Antibiotic Resistance Phenotype ${ }^{1}$ & Source \\
\hline \multicolumn{3}{|c|}{ Pansusceptible } \\
\hline 347-O174:H21 & None & Water \\
\hline 005-O103:H2 & None & Water \\
\hline 007-O103:H2 & None & Water \\
\hline 008-O103:H2 & None & Water \\
\hline 010-O109:H5 & None & Water \\
\hline 033-O34:H32 & None & Water \\
\hline 036-О34:Н32 & None & Water \\
\hline 039-O22:H8 & None & Water \\
\hline 043-O153:NM & None & Water \\
\hline 047-O153:NM & None & Water \\
\hline
\end{tabular}


Table 1. Cont.

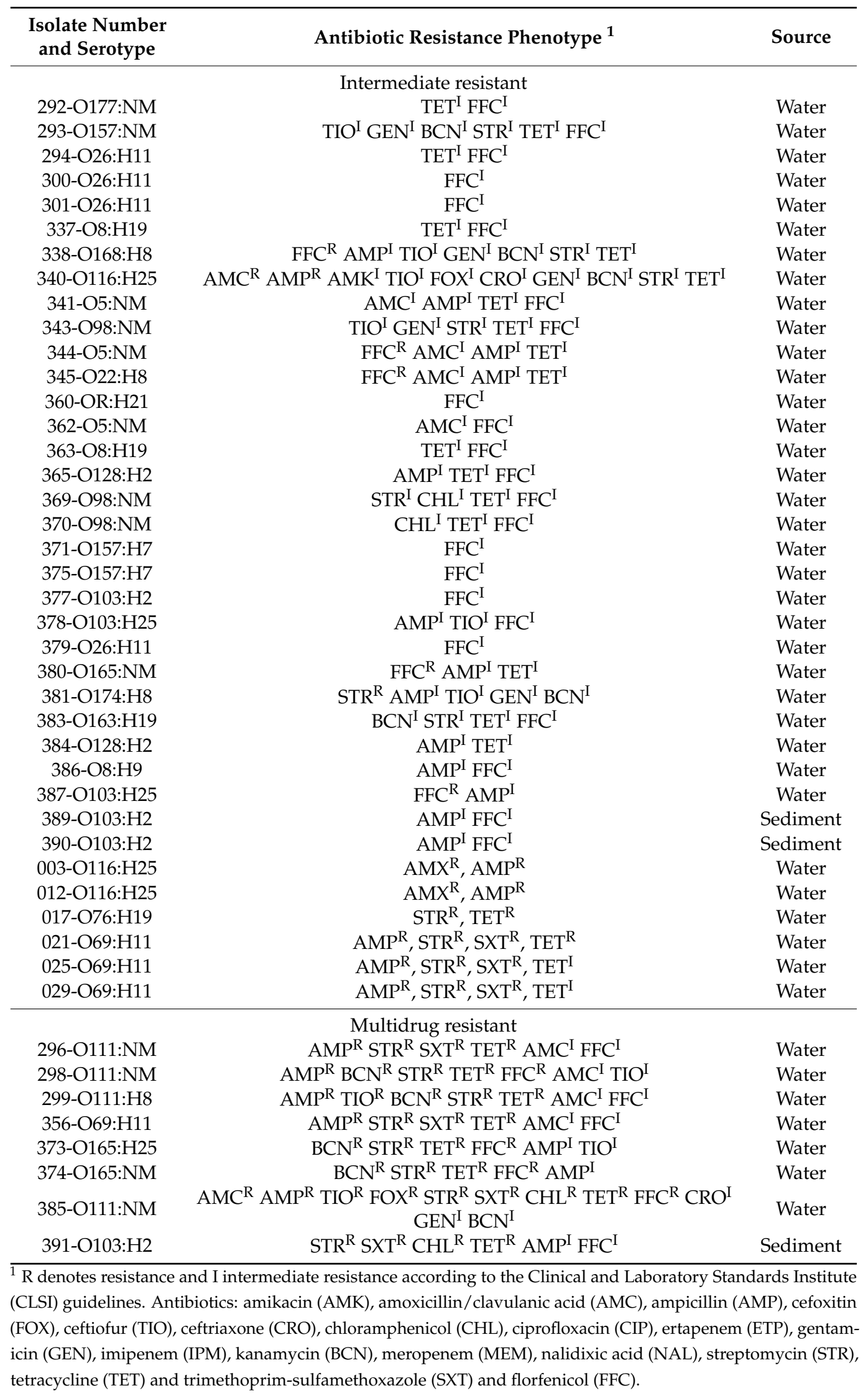




\subsection{Genomic Analysis of the STEC Isolates}

A phylogeny inferred from the analysis of whole genome sequences was indicative of close relationships between isolates within analogous serogroups, as illustrated by the clustering of all O26:H11, O111:H8/NM and O157:H7 isolates from water/sediment and clinical sources (Figure 1). Exceptions were noted for some pairs (O109:H5/O117:H7, O5:NM/O165:H25, O116:H25/O188:H25, O91:H21/O76:H19) that clustered despite differences in serological assignment and are occasionally isolated from human, animal or environmental sources, but reports of human infections caused by strains from these serogroups are infrequent $[30,31]$. Few isolates have been studied in detail and little is known about their phylogenetic relationship to other serogroups. The sequences of some $\mathrm{O}$ gene clusters are known to differ by only a few nucleotides [32]. Hence, clustering of the isolates with different serovars by whole genome SNPs may reflect a true close evolutionary relatedness of isolates representing these different serovars.

A presence-absence matrix displayed next to the tree in Figure 2 illustrates the array of ARDs detected in the genomes of water/sediment and clinical STEC isolates; the prevalence and distribution of specific genes are provided in Table 2. ARDs conferring resistance to phenicols (cat $A$, floR) and fosfomycin (fos $A$ ) were found infrequently. ARDs that encode resistance to sulfonamides (sul1/2), trimethoprim ( $d f r A)$ tetracyclines $($ tet $A / B)$ and aminoglycosides (aac, aad $A$, and $a p h)$ were more common, although the aac aminoglycoside-3-acetyltransferase gene was only detected in a single isolate from water. Narrow-spectrum $\beta$-lactamase $b l a_{\text {TEM-1b }}$ and extended-spectrum AmpC $\beta$-lactamase (cephalosporinase) $b l a_{\mathrm{CMY}-2}$-encoding gene sequences were also present in isolates from both sources, while the extended-spectrum $\beta$-lactamase-encoding bla $a_{\mathrm{CTX}-\mathrm{M}}$ and the chromosomal gyrA83 mutation associated with quinolone/fluoroquinolone resistance were restricted to one and three clinical isolates, respectively. In addition to these acquired mechanisms of $\beta$-lactam resistance, three environmental isolates displayed mutations in the $\operatorname{ampC}$ promoter region. The chloramphenicol resistance effector $c a t A$ was detected in one isolate from water. While macrolide resistance was not measured in the present study, the presence of the $m p h A$ ARD in two environmental isolates was noted in light of reports that suggest the prevalence of the gene is increasing in E. coli [33]. Overall, categorical analysis using Fisher's exact and Bonferroni test indicated that there were no significant differences $(p>0.05)$ in the frequency of ARDs in isolates from either source (Table 2).

The molecular basis of resistance was examined in more detail in the eight MDR isolates. ARDs with a known association to resistance to specific antibiotics are displayed adjacent to the resistance profiles in Table 3. Concordance was observed between phenotype determined in vitro and resistance predicted by in silico analysis in all isolates except $373-$ O165:H25, which was resistant to FFC despite our inability to detect known phenicol ARDs. The intermediate resistance in most isolates could be attributed to the presence of ARDs that impart reduced susceptibility to specific classes of antibiotics. However, none were detected in isolates with intermediate resistance to phenicols, in three isolates with intermediate resistance to the penicillins or penicillin $+\beta$-lactam inhibitors AMP and $\mathrm{AMC}$, and one with intermediate resistance to the cephalosporin TIO. The plasmid replication sequences detected in each MDR isolate are also shown in Table 3. Replicons homologous to sequences in Inc incompatibility groups were detected in all the isolates: IncFII(pRSB107) was detected in three isolates, IncFIB replicons were detected in three isolates, IncFII(pHN7A8), IncFII, and IncQ1 were found in two isolates, and lastly IncX1 and IncY were each detected in one isolate. Replicons homologous to $\mathrm{IncB} / \mathrm{O} / \mathrm{K} / \mathrm{Z}$ were common and were detected in six of eight isolates. ColE1 were identified in three isolates and Col156, a small colicin-encoding ColE-like plasmid which is often referred to as ColE(pIGJC156), was detected in two MDR isolates. 


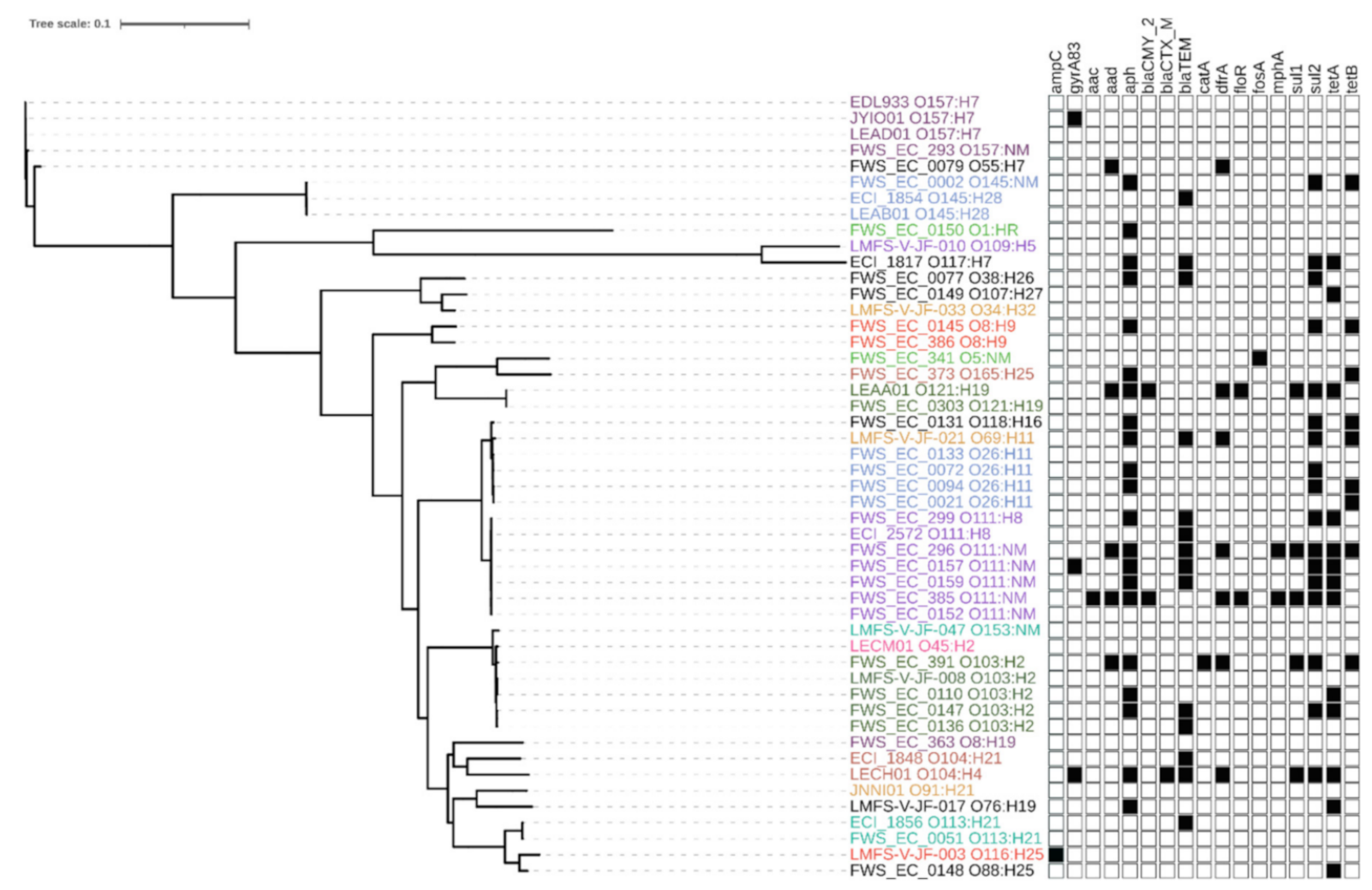

Figure 2. Maximum likelihood phylogeny constructed using core single nucleotide polymorphisms (SNPs) identified among the genomes of 55 STEC isolates recovered from water and sediments (isolate prefix FWS and LMFS) and 112 Canadian clinical STEC isolates and reference strain EDL933. Isolates of the same serotype with identical antimicrobial resistance (AMR) pattern or lacking AMR genes were omitted from the tree; tip colors denote different serotypes. Black squares in the matrix denote the presence of antibiotic resistance determinants common to the isolates. The scale corresponds to the number of substitutions per site. Resistance determinant functions: ampC: mutation in the promoter region of the chromosomal ampC gene; gyrA83 mutation: mutation in DNA gyrase codon 83; aac: aminoglycoside-3-acetyltransferase; aadA: aminoglycoside3-adenylyltransferase; aph: aminoglycoside-3-phosphotransferase; blaCMY-2: AmpC $\beta$-lactamase; blaCTX-M: extendedspectrum $\beta$-lactamase; blaTEM: $\beta$-lactamase; cat $A$ : chloramphenicol acetyltransferase; $d$ fr $A$ : resistance to trimethoprim; floR: florfenicol/chloramphenicol exporter; fos A: fosfomycin thiol transferase; $m p h A$ : macrolide-2-phosphotransferase; sul1: dihydropteroate synthase; sul2: dihydropteroate synthase; tet $A$ : tetracycline efflux protein; tetB: tetracycline efflux protein.

Table 2. Distribution of acquired resistance genes detected in whole genome sequences of 55 STEC isolates recovered from water and sediments in the Lower Mainland of British Columbia, Canada and 112 Canadian clinical STEC isolates. Probabilities that the prevalence of specific genes were nonrandomly distributed were calculated using Fisher's exact test. Resistance determinant functions: ampC: mutation in the promoter region of the chromosomal ampC gene; gyrA83: mutation in DNA gyrase codon 83; aac: aminoglycoside 3-N-acetyltransferase; aadA: aminoglycoside-3-adenylyltransferase; aph: aminoglycoside-3-phosphotransferase; blaCMY-2: $\beta$-lactamase; blaCTX-M: extended spectrum $\beta$-lactamase; blaTEM: $\beta$-lactamase; cat $A$ : chloramphenicol acetyltransferase; $d f r A$ : resistance to trimethoprim; floR: florfenicol/chloramphenicol exporter; fos $A$ : fosfomycin thiol transferase; $m p h A$ : macrolide-2-phosphotransferase; sul1: dihydropteroate synthase; sul2: dihydropteroate synthase; tet $A$ : tetracycline efflux protein; tet $B$ : tetracycline efflux protein.

\begin{tabular}{cccccccc}
\hline & $\begin{array}{c}\text { Prevalence (\%) in } \\
\text { All Isolates }\end{array}$ & \multicolumn{2}{c}{$\begin{array}{c}\text { Water/Sediment } \\
\text { Isolates }\end{array}$} & Clinical Isolates & $\begin{array}{c}p \text { Value } \\
\text { Fisher's Extract }\end{array}$ & $\begin{array}{c}\text { Bonferroni Corrected } \\
p \text { Value }\end{array}$ \\
\hline Gene & & $(+)$ & $(-)$ & $(+)$ & $(-)$ & & 0.034 \\
ampC & 1.80 & 3 & 52 & 0 & 112 & 0.552 & 1.000 \\
gyrA83 & 1.80 & 0 & 55 & 3 & 109 & 0.329 & 1.000 \\
aac & 0.60 & 1 & 54 & 0 & 112 & \\
\hline
\end{tabular}


Table 2. Cont.

\begin{tabular}{cccccccc}
\hline & $\begin{array}{c}\text { Prevalence (\%) in } \\
\text { All Isolates }\end{array}$ & \multicolumn{2}{c}{$\begin{array}{c}\text { Water/Sediment } \\
\text { Isolates }\end{array}$} & \multicolumn{2}{c}{ Clinical Isolates } & $\begin{array}{c}p \text { Value } \\
\text { Fisher's Extract }\end{array}$ & $\begin{array}{c}\text { Bonferroni Corrected } \\
p \text { Value }\end{array}$ \\
\hline Gene & & $(+)$ & $(-)$ & $(+)$ & $(-)$ & & \\
\hline aadA & 32.99 & 3 & 52 & 2 & 110 & 0.333 & 1.000 \\
aph & 16.17 & 12 & 43 & 15 & 97 & 0.184 & 1.000 \\
blaCMY-2 & 1.80 & 1 & 54 & 2 & 110 & 1.000 & 1.000 \\
blaCTX-M & 0.60 & 0 & 55 & 1 & 111 & 1.000 & 1.000 \\
blaTEM & 12.57 & 7 & 48 & 14 & 98 & 1.000 & 1.000 \\
cat $A$ & 0.60 & 1 & 54 & 0 & 112 & 0.329 & 0.000 \\
dfrA & 5.99 & 7 & 48 & 3 & 109 & 0.015 & 1.000 \\
floR & 1.20 & 1 & 54 & 1 & 111 & 0.552 & 1.000 \\
fos $A$ & 2.40 & 3 & 52 & 1 & 111 & 0.105 & 1.000 \\
mph $A$ & 1.20 & 2 & 53 & 0 & 112 & 0.107 & 1.000 \\
sul1 & 2.99 & 3 & 52 & 2 & 110 & 0.333 & 1.000 \\
sul 2 & 13.17 & 9 & 46 & 13 & 99 & 0.466 & 1.000 \\
tet $A$ & 8.98 & 5 & 50 & 10 & 102 & 1000 \\
tetB & 7.78 & 8 & 47 & 5 & 107 & 0.031 & 0.531 \\
\hline
\end{tabular}

Table 3. Acquired resistance determinants (ARDs) and plasmid replicon sequences detected in whole-genome sequences of eight multidrug resistant (MDR) STEC isolates from surface water and sediments.

\begin{tabular}{|c|c|c|c|}
\hline Isolate & $\begin{array}{l}\text { Antibiotic Class/Group and } \\
\text { Resistance Profile }\end{array}$ & $\begin{array}{c}\text { ARDs Detected in the } \\
\text { Sequences and Putative Role in } \\
\text { Resistance }{ }^{1}\end{array}$ & Plasmid Replicon Sequences ${ }^{2,3}$ \\
\hline 296-O111:NM & $\begin{array}{c}\text { Aminoglycosides STR }{ }^{\mathrm{R}} \\
\text { Folate pathway inhibitors SXT } \\
\text { Penicillins, penicillin }+\beta \text {-lactam } \\
\text { inhibitors AMP } \text { AMC }^{\mathrm{I}} \\
\text { Phenicols FFC } \\
\text { Tetracyclines TET } \\
\text { NT }^{\mathrm{R}}\end{array}$ & $\begin{array}{c}\text { aadA2, aph(3")-Ib, aph(6)-Id } \\
\text { drfA8, dfrA12, sul1, sul2 } \\
\text { blaTEM-1B } \\
- \\
\operatorname{tet} A, \text { tet } B \\
\text { mph } A\end{array}$ & $\begin{array}{l}\text { ColE1 (2), IncB/O/K/Z, } \\
\text { IncFII(pHN7A8), IncX1 }\end{array}$ \\
\hline 298-O111:NM & $\begin{array}{c}\text { Aminoglycosides } \mathrm{BCN}^{\mathrm{R}} \mathrm{STR}^{\mathrm{R}} \\
\text { Cephalosporins } \mathrm{TIO}^{\mathrm{I}} \\
\text { Penicillins, penicillin }+\beta \text {-lactam } \\
\text { inhibitors } \\
\text { AMPR }^{\mathrm{R}} \mathrm{AMC}^{\mathrm{I}} \\
\text { Phenicols FFC } \\
\text { Tetracyclines TET } \\
\mathrm{NT}^{\mathrm{R}}\end{array}$ & $\begin{array}{c}\text { aph }\left(3^{\prime}\right)-I a, \text { aph(3")-Ib, aph(6)-Id } \\
\text { blaTEM-1B } \\
\text { blaTEM-1B } \\
- \\
\text { tet } A \\
\text { sul } 2\end{array}$ & $\begin{array}{l}\text { Col156, IncB/O/K/Z, } \\
\text { IncFII(pRSB107), IncQ1 }\end{array}$ \\
\hline 299-O111:H8 & $\begin{array}{c}\text { Aminoglycosides } \mathrm{BCN}^{\mathrm{R}} \mathrm{STR}^{\mathrm{R}} \\
\text { Cephalosprins } \mathrm{TIO}^{\mathrm{R}} \\
\text { Penicillins, penicillin }+\beta \text {-lactam } \\
\text { inhibitors } \\
\text { AMPR }^{\mathrm{R}} \mathrm{AMC}^{\mathrm{I}} \\
\text { Phenicols FFC } \\
\text { Tetracyclines TET } \\
\mathrm{NT}^{\mathrm{R}}\end{array}$ & $\begin{array}{c}\text { aph }\left(3^{\prime}\right)-I a, \text { s aph }\left(3^{\prime \prime}\right)-I b, \text { aph }(6)-I d \\
\text { blaTEM-1B } \\
\text { blaTEM-1B } \\
- \\
\text { tet } A \\
\text { sul } 2\end{array}$ & $\begin{array}{l}\text { Col156, IncB/O/K/Z, } \\
\text { IncFII(pRSB107), IncQ1 }\end{array}$ \\
\hline 356-O69:H11 & $\begin{array}{c}\text { Aminoglycosides STR }{ }^{\mathrm{R}} \\
\text { Folate pathway inhibitors SXT } \\
\text { Penicillins penicillin }+\beta \text {-lactam } \\
\text { inhibitors } \\
\text { AMP }^{\mathrm{R}} \text { AMC }^{\mathrm{I}} \text { Phenicols FFC } \\
\text { Tetracyclines TET }\end{array}$ & $\begin{array}{c}\text { aph(3")-Ib, aph(6)-Id } \\
\text { dfrA8, sul2 } \\
\text { blaTEM-1B } \\
- \\
\text { tetB }\end{array}$ & $\begin{array}{c}\text { IncB/O/K/Z, IncFII(pHN7A8), } \\
\text { IncFIB(AP001918) }\end{array}$ \\
\hline
\end{tabular}


Table 3. Cont.

\begin{tabular}{|c|c|c|c|}
\hline Isolate & $\begin{array}{c}\text { Antibiotic Class/Group and } \\
\text { Resistance Profile }\end{array}$ & $\begin{array}{c}\text { ARDs Detected in the } \\
\text { Sequences and Putative Role in } \\
\text { Resistance }^{1}\end{array}$ & Plasmid Replicon Sequences 2,3 \\
\hline 373-O165:H25 & $\begin{array}{c}\text { Aminoglycosides } \mathrm{BCN}^{\mathrm{R}} \mathrm{STR}^{\mathrm{R}} \\
\text { Cephalosporins } \mathrm{TIO}^{\mathrm{I}} \\
\text { Penicillins AMP } \\
\text { Phenicols FFC } \\
\text { Tetracyclines } \mathrm{TET}^{\mathrm{R}} \\
\end{array}$ & $\begin{array}{c}\operatorname{aph}\left(3^{\prime}\right)-1 a, \operatorname{aph}\left(3^{\prime \prime}\right)-I b, a p h(6)-I d \\
- \\
- \\
- \\
\text { tet } B\end{array}$ & IncFII, IncFIB(AP001918) \\
\hline 374-O165:NM & $\begin{array}{c}\text { Aminoglycosides BCN }{ }^{\mathrm{R}} \mathrm{STR}^{\mathrm{R}} \\
\text { Phenicols FFC } \\
\text { Penicillins AMP } \\
\text { Tetracyclines } \mathrm{TET}^{\mathrm{R}}\end{array}$ & $\begin{array}{c}\operatorname{aph}\left(3^{\prime}\right)-I a, a p h\left(3^{\prime \prime}\right)-I b, a p h(6)-I d \\
- \\
- \\
\text { tetB }\end{array}$ & IncFII, IncFIB(AP001918), \\
\hline 385-O111:NM & $\begin{array}{c}\text { Aminoglycosides } \mathrm{STR}^{\mathrm{R}} \mathrm{BCN}^{\mathrm{I}} \mathrm{GEN}^{\mathrm{I}} \\
\text { Cephalosporins } \mathrm{TIO}^{\mathrm{R}} \mathrm{CRO}^{\mathrm{I}} \\
\text { Cephamycins FOX } \\
\text { Penicillins, penicillin }+\beta \text {-lactam } \\
\text { inhibitors } \\
\text { AMP }^{\mathrm{R}} \mathrm{AMC}^{\mathrm{R}} \\
\text { Folate pathway inhibitors SXT } \\
\text { Phenicols CHL }{ }^{\mathrm{R}} \mathrm{FFC}^{\mathrm{R}} \\
\text { Tetracyclines } \mathrm{TET}^{\mathrm{R}} \\
\mathrm{NT}\end{array}$ & $\begin{array}{c}\text { aac(3)-VIa, aadA1, aadA2, } \\
\text { aph(3")-Ib, } \\
\text { aph(6)-Id } \\
\text { blaCMY-2 } \\
\text { blaCMY-2 } \\
\text { dfrA12, sul1, sul2 } \\
\text { floR } \\
\text { tet } A \\
\text { mphA }\end{array}$ & $\begin{array}{l}\text { ColEI, IncB/O/K/Z, } \\
\text { IncFII(pRSB107), IncY }\end{array}$ \\
\hline 391-O103:H2 & $\begin{array}{c}\text { Aminoglycosides } \mathrm{STR}^{\mathrm{R}} \\
\text { Folate pathway inhibitors SXT } \\
\text { Phenicols CHL } \\
\text { Penicillin } \mathrm{AMC}^{\mathrm{I}} \\
\text { Pel } \\
\text { Tetracyclines } \mathrm{TET}^{\mathrm{R}}\end{array}$ & $\begin{array}{c}\operatorname{aad} A 1, \operatorname{aph}\left(3^{\prime \prime}\right)-I b, \operatorname{aph}(6)-I d \\
\operatorname{dfr} A 1, \text { sul1, sul2 } \\
\text { cat } A 1 \\
- \\
\text { tetB }\end{array}$ & ColEI, IncB $/ \mathrm{O} / \mathrm{K} / \mathrm{Z}$ \\
\hline
\end{tabular}

\footnotetext{
${ }^{1}$ Resistance gene function: aac(3)-VIa: aminoglycoside 3-N-acetyltransferase; aadA1: aminoglycoside-3'-adenylyltransferase; aadA2: aminoglycoside-3-adenylyltransferase; $a p h\left(3^{\prime}\right)$-Ia: aminoglycoside-3- phosphotransferase; aph(3")-1b: aminoglycoside-3-phosphotransferase; aph(6)-Id: aminoglycoside-3-phosphotransferase; blaTEM-1B: $\beta$-lactamase; blaCMY-2: AmpC $\beta$-lactamase-encoding $\beta$-lactamase; catA1: chloramphenicol acetyltransferase; $d f r A 1$ : resistance to trimethoprim; $d r f A 8$ : resistance to trimethoprim; $d f r A 12:$ resistance to trimethoprim; floR: florfenicol/chloramphenicol exporter; $m p h A$ : macrolide-2-phosphotransferase, aph(3")-Ib: streptomycin phosphotransferase; aph(6)-Id: streptomycin phosphotransferase; sul1: dihydropteroate synthase; sul2: dihydropteroate synthase; tet $A$ : tetracycline efflux protein; tet $B$ : tetracycline efflux protein. Some genes are listed multiple times where resistance to drug classes may be induced by the same gene. ${ }^{2}$ Italicized parentheses denote the number of times the sequence was detected in the genome. ${ }^{3}$ Predicted incompatibility group. Plasmid descriptions and putative role: ColEI: small plasmid, colicin-encoding. Col156: small plasmid, colicin-encoding [24,34]; IncB/O/K/Z: MDR and virulence genes [24]; IncFIB(AP001918): MDR and virulence genes [34]; IncFII(pRSB107): MDR and virulence genes [34]; IncFII(pHN7A8): MDR and virulence genes [35]; IncQ1: very broad host range plasmid, MDR genes [34]; IncX1: narrow host range conjugative plasmid, MDR and virulence genes [34,36]; IncY: Phage-like plasmid [34]. ${ }^{4}$ NT: not tested.
}

\section{Discussion}

Data on the prevalence of antibiotic resistance in STEC from either clinical or environmental sources in the province of British Columbia is scarce. Allen et al. [37] reported that 10 E. coli O157:H7 and 15 non- serotype O157 human clinical isolates were susceptible to the second-generation fluoroquinolone ciprofloxacin (CIP) and the carbapenem imipenem (IPM), antimicrobial drugs that are presently listed as Category I based on their very high importance in human medicine [38]. Maal-Bared et al. examined the resistance to six antibiotics in 27 E. coli O157:H7 isolates recovered from water, sediment and biofilms in a British Columbia watershed (Elk Creek) heavily impacted by agriculture and found that all were susceptible to CIP [39]. In the present study, 55 STEC isolates representing different serotypes and recovered from surface water and sediments in four watersheds located in the same region were also susceptible to CIP and the carbapenems IPM, ertapenem (ETP) and meropenem (MEM). Directed studies performed in different countries [40-45] and passive surveillance of laboratory-confirmed O157 STEC in the US [46] indicate that resistance to fluoroquinolones and carbapenems is historically rare in STEC from clinical, animal or food sources. The provincial public health authority (British Columbia Centre for Disease Control, BCCDC) compiles data and analyzes antibiotic resistance trends in 
clinical human E. coli isolates of all pathotypes captured by surveillance programs. A recent report was examined to assess the scope of resistance to Category I antibiotics in strains that cause human infections for comparison with rates measured in the environmental STEC isolates. In 2014, 23.8\% of clinical E. coli isolates were resistant to CIP [47]. CIP is the third most widely prescribed antibiotic in Canada, primarily as a second-line drug for the treatment of persistent human infections (principally of the urinary tract). The response to drug pressure in community and hospital settings is likely contributing to increased resistance to this antibiotic in some human E. coli pathotypes [48,49]. While CIP is no longer licensed for veterinary purposes, use of other fluoroquinolones (eg., danofloxacin, enrofloxacin) persists, primarily for the control of respiratory diseases in cattle and pigs [50]. However, the susceptibility of environmental isolates suggests that the on-farm use of fluoroquinolones is not presently a significant driver of resistance in STEC. The incidence of carbapenamase-producing clinical strains also remains very low in the province [47]. Hence, the prudent use of "last-line agent" carbapenems in human medicine and their prohibition for the treatment, disease prevention and/or growth promotion of farm animals appears to be forestalling resistance to these antibiotics in E. coli from all pathotypes, including STEC.

The susceptibility of environmental STEC to fluoroquinolones and carbapenems was reassuring in light of alarming rates of resistance reported in some jurisdictions. However, resistance or intermediate resistance to other Category I (penicillin- $\beta$-lactamase inhibitor combinations, third generation cephalosporins), high importance Category II (aminoglycosides, penicillins, cephamycins, folate pathway inhibitors) and to several classes of Category III antibiotics was recurrent in comparatively small collections of STEC isolates from the region. The comparison with provincial surveillance data indicated that rates of resistance to penicillins (AMP, 49.8\%, 49.1\%), aminoglycosides (GEN, 9.1\%, $10.9 \%$ ), folate pathway inhibitors (SXT, 24.0\%, 12.7\%) and third generation cephalosporins (cefotaxime, 11.2\%, CRO, 3.6\%) are similar in human clinical E. coli and environmental STEC isolates [47]. Provincial surveillance does not presently provide information about resistance to tetracyclines or phenicols in clinical E. coli. Both are administered to foodproducing animals in Canada to prevent disease and for growth promotion. The Canadian Antimicrobial Resistance Surveillance System (CARSS) captures data on resistance to a range of antibiotics, including tetracyclines and phenicols, in generic E. coli isolated during production, slaughter and in retail meats derived from poultry, swine and cattle [51]. Because the surface waters sampled in this work are situated in a region of intensive livestock production, resistance rates in the environmental STEC were also examined against surveillance data derived from analysis of E. coli from meat animals and their products. Data from 2014 indicate that $55.3 \%$ of generic E. coli were resistant to TET, 32.2\% to AMP, $29.7 \%$ to STR, $12.0 \%$ to STX and $8.1 \%$ to CRO [51]. Reciprocal resistance patterns in clinical [37] and environmental STEC described in previous work [39] and the present study suggests that common selection pressures, modes of transmission and mechanisms are likely driving resistance to antibiotics from these classes in the species. Unfortunately, none of the active surveillance systems capture data on phenicol resistance. CHL is prohibited from use in food producing animals but FFC, a fluorinated derivative of $\mathrm{CHL}$, has a long history of use for the treatment of bovine respiratory diseases and to control pen disease in the local fish farming industry [52]. While $92.7 \%$ of STEC from water and sediments were susceptible to $\mathrm{CHL}, 16.4 \%$ were resistant and $49.1 \%$ were of intermediate resistance to FFC. Surprisingly, the overall prevalence of ARDs associated with resistance to CHL/FFC (floR, $1.20 \%$ ) or CHL (cat $A, 0.60 \%$ ) was very low. Moreover, none were detected in the MDR isolate 373-O165:H25 which was resistant to FFC. Consequently, the extent and molecular basis of resistance to phenicols in the STEC isolates could not be explained on the basis of the analyses performed in the present work and are clearly deserving of further investigation.

In contrast, ARDs associated with resistance to tetracyclines (tet $A / B)$, penicillins (blaTEM), aminoglycosides (aac, aph) and folate pathway inhibitors ( $d f \mathrm{r} A$, sul1/2) were 
detected in the sequences of environmental and clinical STEC at frequencies that were not significantly different $(p>0.05)$. Several studies have shown that sul1/2, dfr, aac, aph, tet $A / B$ and blaTEM ARDs are widely distributed in E. coli from aquatic environments impacted by human activity [53-56]. The $\beta$-lactamase encoding blaTEM-1B was detected at the highest frequency in the present work, although two MDR isolates lacking the ARD were of intermediate resistance to AMP, possibly due to the presence of undetected or unknown efflux pumps which can lessen susceptibility to antibiotics $[57,58]$. The AmpC $\beta$-lactamase encoding blaCMY-2 ARD associated with resistance to third-generation cephalosporins is reported to be widespread in E. coli [59] but was only detected in one MDR isolate (385-O111-NM). Interestingly, this isolate displayed the most complex antibiophenotype and was resistant to both TIO and FFC. The floR gene is often situated on chromosomal DNA, although carriage of both floR and blaCMY-2 on an IncA/C plasmid has been reported $[60,61]$. IncA/C plamids were not detected in the isolates, but other incompatibility types previously shown to carry blaCMY-2 genes in E. coli from human and animal sources were found, including IncB/O and IncFII [24,62].

In conclusion, the analysis of STEC isolates from surface waters and sediments in a region of intensive agricultural activity revealed AR phenotypes and the presence of ARDs comparable to those reported in generic E. coli from food animals. This finding suggests that common selective pressures are contributing to the development of AR in commensal and pathogenic variants of the species, and that aquatic environments can serve as reservoirs for the maintenance of resistant STEC, associated ARDs and their plasmids. Hence, the use of surface waters for the irrigation of food crops could introduce the risk of exposure, particularly in commodities that are commonly consumed raw.

\section{Materials and Methods}

\subsection{Bacterial Strains and Culture Conditions}

STEC isolates $(n=55)$ from 21 different serotypes isolated from surface waters and sediments from four watersheds in a mixed use urban-agricultural landscape located in the Fraser Valley of British Columbia, Canada, by Nadya et al. [29] and Falardeau et al. [63] were examined in this study (Table S1). The isolates were recovered from sampling sites located upstream or downstream of water sources used for the irrigation of various crops, including berry fruits and market vegetables. Samplings were carried out monthly over two years. All isolates were confirmed to be STEC using a hydrophobic grid membrane immunoblot method that targets both Stx1 and Stx2, and the presence of the associated genes was confirmed by multiplex PCR $[29,63]$. E. coli strain ATCC $25922^{\mathrm{TM}}$ was used as a positive control in antibiotic resistance assays (Cedarlane Labs, Burlington, ON, Canada). All strains were stored at $-80{ }^{\circ} \mathrm{C}$ in tryptic soy broth (TSB; Becton, Dickson and Company, Sparks, MD, USA) with $20 \%$ glycerol. Working cultures were prepared by application of thawed cultures to the surface of tryptic Soy agar (TSA; Becton, Dickson and Company), followed by incubation at $37^{\circ} \mathrm{C}$ for $24 \mathrm{~h}$. Working cultures were held at $4{ }^{\circ} \mathrm{C}$ for a maximum of 30 days.

\subsection{Antibiotic Susceptibility Testing}

Susceptibility to antibiotics was determined by the Kirby-Bauer disc diffusion assay [64]. Briefly, $70 \mu \mathrm{L}$ aliquots of 18-24 h cultures grown in Mueller-Hinton broth (Becton, Dickson and Company) at $37{ }^{\circ} \mathrm{C}$ were mixed with $7 \mathrm{~mL}$ of $0.75 \%$ molten agar $\left(44{ }^{\circ} \mathrm{C}\right)$ and added to the surface of petri plates containing Mueller-Hinton agar (Becton, Dickson and Company). The plates were incubated at an ambient temperature for $10 \mathrm{~min}$ and antibiotic discs were applied to the surface of the agar. The zones of inhibition were measured to the nearest millimeter after incubation at $37^{\circ} \mathrm{C}$ for $24 \mathrm{~h}$. The assignment of the isolates to the "susceptible", "intermediate resistance" and "resistant" categories was based on the diameter of the inhibition zone according to the Clinical and Laboratory Standards Institute (CLSI) guidelines [65-67]. E. coli ATCC®25922 ${ }^{\mathrm{TM}}$ was used as the reference strain to verify assay performance. Eighteen antibiotics from several classes 
or groups of antimicrobials used in animal and/or human medicine were tested, including: aminoglycosides (amikacin (AMK; 20/10 $\mu \mathrm{g}$ ), gentamicin (GEN; $10 \mu \mathrm{g}$ ), kanamycin $(\mathrm{BCN} ; 30 \mu \mathrm{g})$, streptomycin (STR; $10 \mu \mathrm{g})$ ); phenicols (chloramphenicol (CHL; $30 \mu \mathrm{g}$ ) and florfenicol (FFC; $30 \mu \mathrm{g})$ ); quinolones (nalidixic acid (NAL; $30 \mu \mathrm{g})$ ); second generation fluoroquinolones (ciprofloxacin (CIP; $5 \mu \mathrm{g})$ ); tetracyclines (tetracycline $\mathrm{HCl}(\mathrm{TET} ; 30 \mu \mathrm{g})$ ); folate pathway inhibitors (trimethoprim-sulfamethoxazole (SXT)); penicillin + B-lactamase inhibitors (amoxicillin/clavulanic acid (AMC; $30 \mu \mathrm{g})$ ); penicillins (ampicillin (AMP; $10 \mu \mathrm{g})$ ); cephamycins (cefoxitin (FOX; $30 \mu \mathrm{g})$ ); third generation cephalosporins (ceftiofur (TIO; $30 \mu \mathrm{g})$, ceftriaxone (CRO; $30 \mu \mathrm{g})$ ); and carbapenems (ertapenem (ETP; $10 \mu \mathrm{g})$, imipenem (IPM; $10 \mu \mathrm{g})$ and meropenem (MEM; $10 \mu \mathrm{g})$ ).

\subsection{Genomic Analyses}

The genomes of the STEC isolates from water/sediment were sequenced and assembled as described in Nadya et al. [31] and Fong et al. [68]. All sequences are available in NCBI's Sequence Read Archive (SRA; http://www.ncbi.nlm.nih.gov/sra/ accessed on 5 January 2021) database under Bioproject Accessions PRJNA287560 and PRJNA649237 [69,70]. De novo assemblies were generated using shovill v. 1.0.94, using gsize 5000000 and mincov of $10 \%$ of the average genome coverage, as determined by the run_assembly_metrics.pl script in CG-pipeline (https:/ / github.com/lskatz/CG-Pipeline accessed on 5 January 2021) [71]. An additional 112 assembled genomes from Canadian human clinical STEC isolates of variable serotypes from the same database were included in some of the analyses for comparative purposes. Tables S1 and S2 provide a list of accession numbers for each isolate, along with resistance genes, mutations and plasmids detected as described below. A single nucleotide polymorphism (SNP) phylogeny was generated using Parsnp v. 1.5.2 with E. coli O157:H7 EDL933 as a reference. The -x option to remove recombination regions was employed. An unrooted tree was visualized using Tree of Life [72]. Isolates of the same serotype with identical AMR pattern or lacking AMR determinants were omitted from the tree. Assemblies were queried for ARDs in the ResFinder database version from 28 October 2020, using staramr v. 0.4.0, with $90 \%$ nucleotide identity and $50 \%$ gene coverage cutoffs. Relevant mutations in the ampC promoter region, gyr $A, g y r B$, parC, and parE were detected by comparing to the PointFinder Database (https: / /bitbucket.org/genomicepidemiology / pointfinder_db/src/master/accessed on 5 January 2021) using ARIBA v 2.12.0 where raw reads were available. For the clinical assemblies, the $\operatorname{ampC}$, the $\operatorname{ampC}$ promoter, $g y r A$, gyrB, parC, and $\operatorname{par} E$ regions were extracted using a perl script (https:/ / github.com/lskatz/lskScripts/blob/master/scripts/ blastAndExtract.pl accessed on 5 January 2021), and subsequently aligned using MUSCLE in Geneious (version 6.0.6, Biomatters Ltd.). Relevant resistance conferring mutations were noted. Plasmid replicons were detected in each assembly using abricate 0.8 .10 and a custom database based off the PlasmidFinder Enterobacteriacae database with a nucleotide identity cutoff of $90 \%$ and a coverage cutoff of $60 \%$ (database fasta available at https: //github.com/StaPH-B/resistanceDetectionCDC/blob/master/plasmidDatabase.fasta accessed on 5 January 2021). Fisher's exact test and Bonferroni correction to correct for multiple testing was calculated using R Studio (version 1.2.1335, http:/ / www.rstudio.com/ accessed on 5 January 2021), and was used to determine if the prevalence of ARDs was non-randomly associated in water/sediment and clinical isolates [73].

Supplementary Materials: The following are available online at https:/ / www.mdpi.com/2079-638 2/10/3/237/s1, Table S1: serotypes, IDs, accession numbers for genomic sequence reads and assemblies, resistance genes, resistance mutations and plasmids identified in Shiga toxigenic Escherichia coli isolates recovered from surface waters and sediments in the Lower Mainland of British Columbia between 2012-2016, Table S2: serotypes, IDs, accession numbers for genomic sequence reads and assemblies, resistance genes, resistance mutations and plasmids identified in Shiga toxigenic Escherichia coli clinical isolates used for comparison of antibiotic resistance gene frequencies. 
Author Contributions: Conceptualization, S.W., K.A. and P.D.; methodology, Y.M., S.W. and P.D.; software, J.C., L.M.C., C.L., M.W. and K.F.; validation, Y.M., P.D. and S.W.; formal analysis, Y.M., S.N., J.C., K.Z. and L.M.C.; investigation, Y.M. and S.N.; resources, S.W., K.A., M.W. and P.D.; data curation, J.C. and C.L.; writing—original draft preparation, Y.M.; writing—review and editing, Y.M., P.D. and S.W.; visualization, Y.M.; supervision, S.W.; project administration, S.W.; funding acquisition, E.T. and S.W. All authors have read and agreed to the published version of the manuscript.

Funding: This research was funded by the Canadian Federal Genomics Research and Development Initiative (GRDI) and the National Sciences and Engineering Research Council of Canada [NSERC Discovery Grant RGPIN-2015-04871]. We acknowledge the contributions of the GRDI-Food and Water Safety Consortium (comprised of researchers from Agriculture and Agri-Food Canada, the Canadian Food Inspection Agency, Environment Canada, Health Canada, the National Research Council of Canada, and the Public Health Agency of Canada) for useful discussions and contributions.

Data Availability Statement: All data derived from the study are provided in the article and in supplementary material.

Acknowledgments: We gratefully acknowledge the help provided by Adam Olson of the PHAC National Microbiology Laboratory, Winnipeg, Manitoba for invaluable assistance with the sequencing, assembly, and annotation of STEC genomes.

Conflicts of Interest: The authors declare no conflict of interest. The funders had no role in the design of the study; in the collection, analyses, or interpretation of data; in the writing of the manuscript, or in the decision to publish the results.

\section{References}

1. Riley, L.W.; Remis, R.S.; Helgerson, S.D.; McGee, H.B.; Wells, J.G.; Davis, B.R.; Hebert, R.J.; Olcott, E.S.; Johnson, L.M.; Hargrett, N.T.; et al. hemorrhagic colitis associated with a rare Escherichia coli serotype. N. Engl. J. Med. 1983, 308, 681-685. [CrossRef] [PubMed]

2. Tarr, P.I.; Gordon, C.A.; Chandler, W.L. Shiga-toxin-producing Escherichia coli and haemolytic uraemic syndrome. Lancet 2005, 365, 1073-1086. [CrossRef]

3. Nathanson, S.; Kwon, T.; Elmaleh, M.; Charbit, M.; Launay, E.A.; Harambat, J.; Brun, M.; Ranchin, B.; Bandin, F.; Cloarec, S.; et al. Acute neurological involvement in diarrhea-associated hemolytic uremic syndrome. Clin. J. Am. Soc. Nephrol. 2010, 5, 1218-1228. [CrossRef] [PubMed]

4. Melton-Celsa, A.; Mohawk, K.; Teel, L.; O’Brien, A. Pathogenesis of Shiga-Toxin Producing Escherichia coli; Springer: Berlin/Heidelberg, Germany, 2011; Volume 357, pp. 67-103.

5. Pires, S.M.; Majowicz, S.; Gill, A.; Devleesschauwer, B. Global and regional source attribution of Shiga toxin-producing Escherichia coli infections using analysis of outbreak surveillance data. Epidemiol. Infect. 2019, 147, e236. [CrossRef]

6. Goldwater, P.N.; Bettelheim, K.A. Treatment of enterohemorrhagic Escherichia coli (EHEC) infection and hemolytic uremic syndrome (HUS). BMC Med. 2012, 10, 12. [CrossRef]

7. Zhang, X.; McDaniel, A.D.; Wolf, L.E.; Keusch, G.T.; Waldor, M.K.; Acheson, D.W.K. Quinolone antibiotics induce shiga toxin-encoding bacteriophages, toxin production, and death in mice. J. Infect. Dis. 2000, 181, 664-670. [CrossRef]

8. Agger, M.; Scheutz, F.; Villumsen, S.; Mølbak, K.; Petersen, A.M. Antibiotic treatment of verocytotoxin-producing Escherichia coli (VTEC) infection: A systematic review and a proposal. J. Antimicrob. Chemother. 2015, 70, 2440-2446. [CrossRef]

9. Menne, J.; Nitschke, M.; Stingele, R.; Abu-Tair, M.; Beneke, J.; Bramstedt, J.; Bremer, J.P.; Brunkhorst, R.; Busch, V.; Dengler, R.; et al. Validation of treatment strategies for enterohaemorrhagic Escherichia coli O104:H4 induced haemolytic uraemic syndrome: Case-control study. BMJ 2012, 345, e4565. [CrossRef]

10. Wieler, L.H.; Bauerfeind, R. STEC as a veterinary problem. Diagnostics and prophylaxis in animals. Methods Mol. Med. 2003, 73, 75-89. [PubMed]

11. Premanandh, J.; Samara, B.S.; Mazen, A.N. Race against antimicrobial resistance requires coordinated action-An overview. Front. Microbiol. 2016, 6, 1536. [CrossRef]

12. Laxminarayan, R.; Duse, A.; Wattal, C.; Zaidi, A.K.M.; Wertheim, H.F.L.; Sumpradit, N.; Vlieghe, E.; Hara, G.L.; Gould, I.M.; Goossens, H.; et al. Antibiotic resistance-The need for global solutions. Lancet Infect. Dis. 2013, 13, 1057-1098. [CrossRef]

13. World Health Organization (WHO). Antimicrobial Resistance Global Report on Surveillance 2014. Available online: http: //www.who.int/drugresistance/documents/surveillancereport/en (accessed on 18 January 2021).

14. Kim, H.H.; Samadpour, M.; Grimm, L.; Clausen, C.R.; Besser, T.E.; Baylor, M.; Kobayashi, J.M.; Neill, M.A.; Schoenknecht, F.D.; Tarr, P.I. Characteristics of antibiotic-resistant Escherichia coli O157:H7 in Washington State, 1984-1991. J. Infect. Dis. 1994, 170, 1606-1609. [CrossRef]

15. Zhao, S.; White, D.G.; Ge, B.; Ayers, S.; Friedman, S.; English, L.; Wagner, D.; Gaines, S.; Meng, J. Identification and characterization of integron-mediated antibiotic resistance among Shiga toxin-producing Escherichia coli isolates. Appl. Environ. Microbiol. 2001, 67, 1558-1564. [CrossRef] [PubMed] 
16. Singh, R.; Schroeder, C.M.; Meng, J.; White, D.G.; McDermott, P.F.; Wagner, D.D.; Yang, H.; Simjee, S.; Debroy, C.; Walker, R.D.; et al. Identification of antimicrobial resistance and class 1 integrons in Shiga toxin-producing Escherichia coli recovered from humans and food animals. J. Antimicrob. Chemother. 2005, 56, 216-219. [CrossRef]

17. Murinda, S.E.; Ebner, P.D.; Nguyen, L.T.; Mathew, A.G.; Oliver, S.P. Antimicrobial resistance and class 1 integrons in pathogenic Escherichia coli from dairy farms. Foodborne Pathog. Dis. 2005, 2, 348-352. [CrossRef] [PubMed]

18. Guerra, B.; Junker, E.; Schroeter, A.; Helmuth, R.; Guth, B.E.C.; Beutin, L. Phenotypic and genotypic characterization of antimicrobial resistance in Escherichia coli O111 isolates. J. Antimicrob. Chemother. 2006, 57, 1210-1214. [CrossRef]

19. Karmali, M.A.; Gannon, V.; Sargeant, J.M. Verocytotoxin-producing Escherichia coli (VTEC). Vet. Microbiol. 2010, 140, 360-370. [CrossRef] [PubMed]

20. Magiorakos, A.-P.; Srinivasan, A.; Carey, R.B.; Carmeli, Y.; Falagas, M.E.; Giske, C.G.; Harbarth, S.; Hindler, J.F.; Kahlmeter, G.; Olsson-Liljequist, B.; et al. Multidrug-resistant, extensively drug-resistant and pandrug-resistant bacteria: An international expert proposal for interim standard definitions for acquired resistance. Clin. Microbiol. Infect. 2012, 18, 268-281. [CrossRef]

21. Blair, J.M.A.; Webber, M.A.; Baylay, A.J.; Ogbolu, D.O.; Piddock, L.J.V. Molecular mechanisms of antibiotic resistance. Nat. Rev. Microbiol. 2015, 13, 42-51. [CrossRef] [PubMed]

22. Stokes, H.W.; Hall, R.M. A novel family of potentially mobile DNA elements encoding site-specific gene-integration functions: Integrons. Mol. Microbiol. 1989, 3, 1669-1683. [CrossRef] [PubMed]

23. Gillings, M.R. Integrons: Past, Present, and Future. Microbiol. Mol. Biol. Rev. 2014, 78, 257-277. [CrossRef]

24. Carattoli, A. Resistance plasmid families in Enterobacteriaceae. Antimicrob. Agents Chemother. 2009, 53, 2227-2238. [CrossRef] [PubMed]

25. Shintani, M.; Sanchez, Z.K.; Kimbara, K. Genomics of microbial plasmids: Classification and identification based on replication and transfer systems and host taxonomy. Front. Microbiol. 2015, 6, 242. [CrossRef] [PubMed]

26. Losada, L.; Debroy, C.; Radune, D.; Kim, M.; Sanka, R.; Brinkac, L.M.; Kariyawasam, S.; Shelton, D.R.; Fratamico, P.M.; Kapur, V.; et al. Whole genome sequencing of diverse Shiga toxin-producing and non-producing Escherichia coli strains reveals a variety of virulence and novel antibiotic resistance plasmids. Plasmid 2016, 83, 8-11. [CrossRef]

27. Köser, C.U.; Ellington, M.J.; Peacock, S.J. Whole-genome sequencing to control antimicrobial resistance. Trends Genet. 2014, 30, 401-407. [CrossRef]

28. Tyson, G.H.; McDermott, P.F.; Li, C.; Chen, Y.; Tadesse, D.A.; Mukherjee, S.; Bodeis-Jones, S.; Kabera, C.; Gaines, S.A.; Loneragan, G.H.; et al. WGS accurately predicts antimicrobial resistance in Escherichia coli. J. Antimicrob. Chemother. 2015, 70, 2763-2769. [CrossRef]

29. Nadya, S.; Delaquis, P.; Chen, J.; Allen, K.; Johnson, R.P.; Ziebell, K.; Laing, C.; Gannon, V.; Bach, S.; Topp, E. Phenotypic and genotypic characteristics of Shiga toxin-producing Escherichia coli isolated from surface waters and sediments in a Canadian urban-agricultural landscape. Front. Cell. Infect. Microbiol. 2016, 6, 36. [CrossRef] [PubMed]

30. Hussein, H.S. Prevalence and pathogenicity of Shiga toxin-producing Escherichia coli in beef cattle and their products. J. Anim. Sci. 2007, 85, E63-E72. [CrossRef]

31. Bai, X.; Hu, B.; Xu, Y.; Sun, H.; Zhao, A.; Ba, P.; Fu, S.; Fan, R.; Jin, Y.; Wang, H.; et al. Molecular and phylogenetic characterization of non-O157 Shiga toxin-producing Escherichia coli strains in China. Front. Cell. Infect. Microbiol. 2016, 6, 143. [CrossRef] [PubMed]

32. Liu, Y.; Fratamico, P.; Debroy, C.; Bumbaugh, A.C.; Allen, J.W. DNA Sequencing and identification of serogroup-specific genes in the Escherichia coli $\mathrm{O} 118 \mathrm{O}$ antigen gene cluster and demonstration of antigenic diversity but only minor variation in DNA sequence of the $\mathrm{O}$ antigen clusters of E. coli O118 and O151. Foodborne Pathog. Dis. 2008, 5, 449-457. [CrossRef] [PubMed]

33. Wu, G.; Day, M.J.; Mafura, M.T.; Nunez-Garcia, J.; Fenner, J.J.; Sharma, M.; Van Essen-Zandbergen, A.; Rodríguez, I.; Dierikx, C.; Kadlec, K.; et al. Comparative analysis of ESBL-positive Escherichia coli isolates from animals and humans from the UK, The Netherlands and Germany. PLoS ONE 2013, 8, e75392. [CrossRef] [PubMed]

34. Johnson, T.J.; Nolan, L.K. Pathogenomics of the Virulence Plasmids of Escherichia coli. Microbiol. Mol. Biol. Rev. 2009, 73, 750-774. [CrossRef]

35. He, L.; Partridge, S.R.; Yang, X.; Hou, J.; Deng, Y.; Yao, Q.; Zeng, Z.; Chen, Z.; Liu, J. Complete nucleotide sequence of pHN7A8, an F33:A-:B- type epidemic plasmid carrying blaCTX-M-65, fosA3 and rmtB from China. J. Antimicrob. Chemother. 2013, 68, 46-50. [CrossRef]

36. Johnson, T.J.; Bielak, E.M.; Fortini, D.; Hansen, L.H.; Hasman, H.; Debroy, C.; Nolan, L.K.; Carattoli, A. Expansion of the IncX plasmid family for improved identification and typing of novel plasmids in drug-resistant Enterobacteriaceae. Plasmid 2012, 68, 43-50. [CrossRef]

37. Allen, K.J.; Laing, C.R.; Cancarevic, A.; Zhang, Y.; Mesak, L.R.; Xu, H.; Paccagnella, A.; Gannon, V.P.J.; Hoang, L. Characteristics of clinical Shiga toxin-producing Escherichia coli Isolated from British Columbia. BioMed Res. Int. 2013, 2013, 1-11. [CrossRef]

38. Health Canada. Categorization of Antimicrobial Drugs Based on Importance in Human Medicine. Available online: https:/ / www.canada.ca/en/health-canada/services/drugs-health-products/veterinary-drugs/antimicrobial-resistance / categorization-antimicrobial-drugs-based-importance-human-medicine.html (accessed on 18 January 2021).

39. Maal-Bared, R.; Bartlett, K.H.; Bowie, W.R.; Hall, E.R. Phenotypic antibiotic resistance of Escherichia coli and E. coli O157 isolated from water, sediment and biofilms in an agricultural watershed in British Columbia. Sci. Total. Environ. 2013, 443, 315-323. [CrossRef] [PubMed] 
40. Meng, J.; Zhao, S.; Doyle, M.P.; Joseph, S.W. Antibiotic resistance of Escherichia coli O157:H7 and O157:NM isolated from animals, food, and humans. J. Food Prot. 1998, 61, 1511-1514. [CrossRef]

41. Cabal, A.; Gómez-Barrero, S.; Porrero, C.; Bárcena, C.; López, G.; Cantón, R.; Gortazar, C.; Domínguez, L.; Alvarez, J. Assessment of virulence factors characteristic of human Escherichia coli pathotypes and antimicrobial resistance in O157:H7 and non-O157:H7 isolates from livestock in Spain. Appl. Environ. Microbiol. 2013, 79, 4170-4172. [CrossRef]

42. Krüger, A.; Lucchesi, P.M.A.; Sanso, A.M.; Etcheverría, A.I.; Bustamante, A.V.; Burgán, J.; Fernández, L.; Fernandez, D.; Leotta, G.; Friedrich, A.W.; et al. Genetic characterization of Shiga toxin-producing Escherichia coli O26:H11 strains isolated from animal, food, and clinical samples. Front. Cell. Infect. Microbiol. 2015, 5, 74. [CrossRef]

43. Amézquita-López, B.A.; Quiñones, B.; Soto-Beltrán, M.; Lee, B.G.; Yambao, J.C.; Lugo-Melchor, O.Y.; Chaidez, C. Antimicrobial resistance profiles of Shiga toxin-producing Escherichia coli O157 and Non-O157 recovered from domestic farm animals in rural communities in Northwestern Mexico. Antimicrob. Resist. Infect. Control. 2016, 5, 1-6. [CrossRef] [PubMed]

44. Day, M.; Doumith, M.; Jenkins, C.; Dallman, T.J.; Hopkins, K.L.; Elson, R.; Godbole, G.; Woodford, N. Antimicrobial resistance in Shiga toxin-producing Escherichia coli serogroups O157 and O26 isolated from human cases of diarrhoeal disease in England, 2015. J. Antimicrob. Chemother. 2017, 72, 145-152. [CrossRef] [PubMed]

45. Mora, A.; Blanco, J.E.; Blanco, M.; Alonso, M.P.; Dhabi, G.; Echeita, A.; González, E.A.; Bernárdez, M.I.; Blanco, J. Antimicrobial resistance of Shiga toxin (verotoxin)-producing Escherichia coli O157:H7 and non-O157 strains isolated from humans, cattle, sheep and food in Spain. Res. Microbiol. 2005, 156, 793-806. [CrossRef]

46. Centers for Disease Control and Prevention (CDC). National Antimicrobial Resistance Monitoring System for Enteric Bacteria. Available online: https:/ / www.cdc.gov/narms/index.html (accessed on 18 January 2021).

47. British Columbia Center of Disease Control (BCCDC). Antimicrobial Resistance Trends in the Province of British Columbia. 2014. Available online: http:/ / www.bccdc.ca/resource-gallery /Documents / AMR\%202014\%20Report-3NOV2015_FINAL.pdf (accessed on 18 January 2021).

48. Redgrave, L.S.; Sutton, S.B.; Webber, M.A.; Piddock, L.J. Fluoroquinolone resistance: Mechanisms, impact on bacteria, and role in evolutionary success. Trends Microbiol. 2014, 22, 438-445. [CrossRef]

49. Fasugba, O.; Gardner, A.; Mitchell, B.G.; Mnatzaganian, G. Ciprofloxacin resistance in community-and hospital-acquired Escherichia coli urinary tract infections: A systematic review and meta-analysis of observational studies. BMC Infect. Dis. 2015, 15, 545. [CrossRef]

50. Public Health Agency of Canada (PHAC). Human Antimicrobial Use Report. 2014. Available online: https://www.canada ca/en/public-health/services / publications/drugs-health-products/human-antimicrobial-use-report-2014.html (accessed on 1 February 2021).

51. Public Health Agency of Canada (PHAC). Antimicrobial Resistance Surveillance System (CARSS) Report. 2016. Available online: https:/ / www.canada.ca/en/public-health/services/publications/drugs-health-products/canadian-antimicrobial-resistancesurveillance-system-report-2016.html (accessed on 1 February 2021).

52. Morrison, D.B.; Saksida, S. Trends in antimicrobial use in Marine Harvest Canada farmed salmon production in British Columbia (2003-2011). Can. Vet. J. 2013, 54, 1160-1163. [PubMed]

53. Gomi, R.; Matsuda, T.; Matsumura, Y.; Yamamoto, M.; Tanaka, M.; Ichiyama, S.; Yoneda, M. Whole-genome analysis of antimicrobial-resistant and extraintestinal pathogenic Escherichia coli in river water. Appl. Environ. Microbiol. 2017, 83, e02703-16. [CrossRef]

54. Hamelin, K.; Bruant, G.; El-Shaarawi, A.; Hill, S.; Edge, T.A.; Fairbrother, J.; Harel, J.; Maynard, C.; Masson, L.; Brousseau, R. Occurrence of virulence and antimicrobial resistance genes in Escherichia coli isolates from different aquatic ecosystems within the St. Clair River and Detroit River Areas. Appl. Environ. Microbiol. 2006, 73, 477-484. [CrossRef] [PubMed]

55. Stange, C.; Sidhu, J.; Tiehm, A.; Toze, S. Antibiotic resistance and virulence genes in coliform water isolates. Int. J. Hyg. Environ. Health 2016, 219, 823-831. [CrossRef]

56. Von Wintersdorff, C.J.H.; Penders, J.; Van Niekerk, J.M.; Mills, N.D.; Majumder, S.; Van Alphen, L.B.; Savelkoul, P.H.M.; Wolffs, P.F.G. Dissemination of antimicrobial resistance in microbial ecosystems through horizontal gene transfer. Front. Microbiol. 2016, 7, 173. [CrossRef]

57. van Hoek, A.H.; Mevius, D.; Guerra, B.; Mullany, P.; Roberts, A.P.; Aarts, H.J. Acquired antibiotic resistance genes: An overview. Front. Microbiol. 2011, 2, 1-203.

58. Poole, K. Efflux-mediated antimicrobial resistance. In Antibiotic Discovery and Development; Dougherty, T.J., Pucci, M.J., Eds.; Springer: Boston, MA, USA, 2012; pp. 349-395.

59. Jacoby, G.A. AmpC $\beta$-lactamases. Clin. Microbiol. Rev. 2009, 22, 161-182. [CrossRef]

60. Blickwede, M.; Schwarz, S. Molecular analysis of florfenicol-resistant Escherichia coli isolates from pigs. J. Antimicrob. Chemother. 2004, 53, 58-64. [CrossRef] [PubMed]

61. Meunier, D.; Jouy, E.; Lazizzera, C.; Doublet, B.; Kobisch, M.; Cloeckaert, A.; Madec, J.-Y. Plasmid-borne florfenicol and ceftiofur resistance encoded by the floR and blaCMY-2 genes in Escherichia coli isolates from diseased cattle in France. J. Med. Microbiol. 2010, 59, 467-471. [CrossRef] [PubMed]

62. Bortolaia, V.; Hansen, K.H.; Nielsen, C.A.; Fritsche, T.R.; Guardabassi, L. High diversity of plasmids harbouring blaCMY-2 among clinical Escherichia coli isolates from humans and companion animals in the upper Midwestern USA. J. Antimicrob. Chemother. 2014, 69, 1492-1496. [CrossRef] [PubMed] 
63. Falardeau, J.; Johnson, R.P.; Pagotto, F.; Wang, S. Occurrence, characterization, and potential predictors of verotoxigenic Escherichia coli, Listeria monocytogenes, and Salmonella in surface water used for produce irrigation in the Lower Mainland of British Columbia, Canada. PLoS ONE 2017, 12, e0185437. [CrossRef]

64. Bauer, A.W.; Kirby, W.M.; Sherris, J.C.; Turck, M. Antibiotic susceptibility testing by a standardized single disk method. Tech. Bull. Regist. Med. Technol. 1966, 36, 49. [CrossRef]

65. Clinical and Laboratory Standards Institute (CLSI). Performance Standards for Antimicrobial Susceptibility Testing: Twenty-First Informational Supplement; CLSI Document M100-S21; Clinical and Laboratory Standards Institute: Wayne, PA, USA, 2011; ISBN 1-56238-742-1.

66. Clinical and Laboratory Standards Institute (CLSI). Performance Standards for Antimicrobial Disk and Dilution Susceptibility Tests for Bacteria Isolated From Animals, 5th ed.; Clinical and Laboratory Standards Institute: Wayne, PA, USA, 2018; ISBN 978-1-68440-009-6.

67. Ahmed, M.O.; Clegg, P.D.; Williams, N.J.; Baptiste, K.E.; Bennett, M. Antimicrobial resistance in equine faecal Escherichia coli isolates from North West England. Ann. Clin. Microbiol. Antimicrob. 2010, 9, 12. [CrossRef]

68. Fong, K.; Lu, Y.T.L.; Brenner, T.; Falardeau, J.; Wang, S. CRISPR and prophage diversity across Salmonella \& verotoxin-producing Escherichia coli. BMC Genom. 2021.

69. Leinonen, R.; Sugawara, H.; Shumway, M.; International Nucleotide Sequence Database Collaboration. The sequence read archive. Nucleic Acids Res. 2011, 39, D19-D21. [CrossRef]

70. Barrett, T.; Clark, K.; Gevorgyan, R.; Gorelenkov, V.; Gribov, E.; Karsch-Mizrachi, I.; Kimelman, M.; Pruitt, K.D.; Resenchuk, S.; Tatusova, T.; et al. BioProject and BioSample databases at NCBI: Facilitating capture and organization of metadata. Nucleic Acids Res. 2012, 40, D57-D63. [CrossRef] [PubMed]

71. Kislyuk, A.O.; Katz, L.S.; Agrawal, S.; Hagen, M.S.; Conley, A.B.; Jayaraman, P.; Nelakuditi, V.; Humphrey, J.C.; Sammons, S.A.; Govil, D.; et al. A computational genomics pipeline for prokaryotic sequencing projects. Bioinformatics 2010, 26, 1819-1826. [CrossRef]

72. Letunic, I.; Bork, P. Interactive Tree of Life (iTOL) v4: Recent updates and new developments. Nucleic Acids Res. 2019, 47, W256-W259. [CrossRef] [PubMed]

73. Walter, J.; Noll, I.; Feig, M.; Weiss, B.; Claus, H.; Werner, G.; Eckmanns, T.; Hermes, J.; Abu Sin, M. Decline in the proportion of methicillin resistance among Staphylococcus aureus isolates from non-invasive samples and in outpatient settings, and changes in the co-resistance profiles: An analysis of data collected within the Antimicrobial Resistance Surveillance Network, Germany 2010 to 2015. BMC Infect. Dis. 2017, 17, 169. [CrossRef] 